\title{
Crest, Saint-Antoine
}

Voie communale

\section{Christine Ronco}

\section{(2) OpenEdition}

12 Journals

Édition électronique

URL : http://journals.openedition.org/adlfi/1686

ISSN : 2114-0502

Éditeur

Ministère de la culture

Référence électronique

Christine Ronco, "Crest, Saint-Antoine », ADLFI. Archéologie de la France - Informations [En ligne], Rhône-Alpes, mis en ligne le 01 mars 2008, consulté le 19 avril 2019. URL : http:// journals.openedition.org/adlfi/1686

Ce document a été généré automatiquement le 19 avril 2019

(C) Ministère de la Culture et de la Communication, CNRS 


\title{
Crest, Saint-Antoine
}

\author{
Voie communale
}

\author{
Christine Ronco
}

\section{Identifiant de l'opération archéologique : 9942}

Date de l'opération : 2008 (EX)

1 Des sondages ont permis de mettre en évidence une occupation de la fin de l'Antiquité ou du début du Moyen Âge au sud de la parcelle. Elle est caractérisée par des structures en creux de type fosses et trous de poteaux associées à un niveau d'occupation d'une vingtaine de centimètres d'épaisseur. Les murs sont constitués de blocs de calcaire non maçonnés à la base, sans doute surmontés d'une élévation en terre. La démolition très riche en blocs peut masquer un certain nombre de murs du même type difficilement observables lors d'un diagnostic. La datation proposée reste imprécise en raison du manque de mobilier datant. Le site est toutefois bien circonscrit au sud de la parcelle. Cette occupation semble correspondre à un habitat rural, mais aucune trace d'établissement religieux et de cimetière, attendu dans ce secteur, n'a été observée. Par ailleurs, au nord-ouest de la parcelle, deux fosses installées directement dans le terrain naturel sont apparues. La céramique non tournée, très mal conservée, associée à ces structures évoque une datation protohistorique, ce qui rend probable la présence d'une autre occupation plus ancienne sans doute arasée, sur cette parcelle.

Christine RONCO 
INDEX

Index chronologique : Antiquité romaine, Moyen Âge, Protohistoire Index géographique : Rhône-Alpes, Drôme (26), Crest

Thèmes : céramique protohistorique, fosse, habitat rural, trou de poteau operation Expertise (EX)

\section{AUTEUR}

\section{CHRISTINE RONCO}

INRAP 